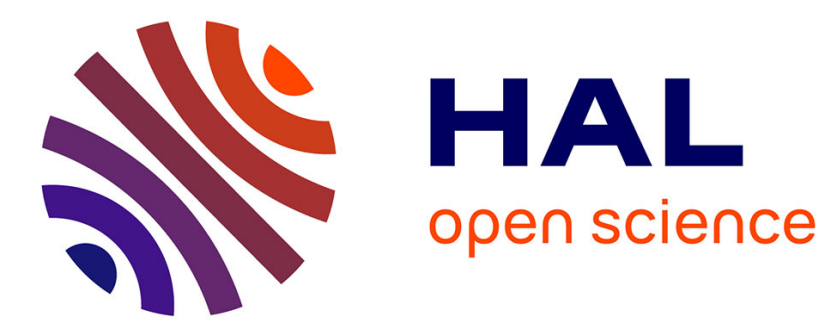

\title{
Radio Wave Propagation Characterization Between Adjacent Decks on Board Ships
}

H Farhat, H Kdouh, C Brousseau, Gheorghe I. Zaharia, G Grunfelder, Ghais El Zein

\section{- To cite this version:}

H Farhat, H Kdouh, C Brousseau, Gheorghe I. Zaharia, G Grunfelder, et al.. Radio Wave Propagation Characterization Between Adjacent Decks on Board Ships. Vehicular Technology Conference VTC2015-Fall, Sep 2015, Boston, United States. 10.1109/VTCFall.2015.7391107 . hal-01196047

\section{HAL Id: hal-01196047 \\ https://hal.science/hal-01196047}

Submitted on 9 Sep 2015

HAL is a multi-disciplinary open access archive for the deposit and dissemination of scientific research documents, whether they are published or not. The documents may come from teaching and research institutions in France or abroad, or from public or private research centers.
L'archive ouverte pluridisciplinaire HAL, est destinée au dépôt et à la diffusion de documents scientifiques de niveau recherche, publiés ou non, émanant des établissements d'enseignement et de recherche français ou étrangers, des laboratoires publics ou privés. 


\section{Radio Wave Propagation Characterization Between Adjacent Decks on Board Ships}

\author{
H. Farhat \\ University Institute of Technology \\ Lebanese University \\ Saida, Lebanon \\ hannafarhat@hotmail.com
}

\author{
H. Kdouh, C. Brousseau, G. Zaharia, G. Grunfelder \\ and G. El Zein \\ IETR - Rennes \\ Rennes, France \\ Hussein.kdouh@insa-rennes.fr
}

\begin{abstract}
The objective of this paper is to characterize the electromagnetic waves propagation between adjacent decks on board a ship. First, narrowband measurements were conducted at $2.45 \mathrm{GHz}$ to study the radio coverage. Then, double directional channel measurements were performed at $3.5 \mathrm{GHz}$ to determine the propagation mechanisms in this hostile environment. The aim of these measurement campaigns is to find a solution to maintain the connectivity of a wireless sensor network between different decks on a ship in spite of the metallic structure of decks.
\end{abstract}

Keywords—wave propagation; channel sounding; ships

\section{INTRODUCTION}

A possible solution to reduce the kilometers of cables used to connect thousands of sensors to control units on board ships is the use of Wireless Sensor Networks (WSNs). Moreover, ferry companies aim to enhance the passenger satisfaction by equipping their boats with $\mathrm{WiFi}$ networks. However, the metallic structure of ships severely limits the propagation of Electromagnetic (EM) waves between two points within a ship, especially between adjacent rooms, and between adjacent decks. Therefore, it is necessary to study the EM waves propagation in this particular environment in order to optimize the radio devices placement. A few works have verified the feasibility of wireless communications on board ships [1]. However, spatio-temporal characterization of EM waves propagation between adjacent decks has not been investigated yet. In this paper, we will study the critical communication scenario, in which the transmitter (Tx) and the receiver $(\mathrm{Rx})$ are located in two adjacent decks. First, narrowband measurements were conducted at $2.45 \mathrm{GHz}$ to study the radio coverage. Then, wideband double directional channel [2] measurements were performed at $3.5 \mathrm{GHz}$ to determine the main propagation mechanisms in this particular configuration. The results can be used to determine the wireless devices best location in order to maintain the connectivity of a shipboard wireless network covering different decks.

This paper is organized as follows. In section II, we present the narrowband measurement results. Then, in section III, the double directional channel measurement results are described. Finally, section IV concludes this paper and draws some perspectives of this work.

\section{NARROWBAND CHANNEL MEASUREMENTS}

Due to the low data rate of a shipboard WSN, Continuous Wave (CW) measurements are sufficient to characterize the radio coverage of a WSN because the bandwidth of the transmitted signal is much less than the coherence bandwidth of the propagation channel. CW measurements were conducted on the 8th and 9th passenger decks (D8 and D9) of the "Armorique" ferry. The Tx is constituted of a signal generator which delivers $0 \mathrm{dBm} \mathrm{CW}$ signal at $2.45 \mathrm{GHz}$. The $\mathrm{Rx}$ is composed of a spectrum analyzer operating in zero-span mode and an antenna positioner. Two omnidirectional conical monopole antennas (vertically polarized) were used at the Tx and Rx. The Tx is located in a stairway of D8 and the Rx is successively located at four different locations on D9. To minimize the multipath fading effect, the received power values were averaged along 20 wavelength circular track using 250 power samples. Fig. 1 shows the layout of D8 and D9, the Tx location at $\mathrm{D} 8$ and $\mathrm{Rx}$ locations $(\mathrm{Rx} 1$ to $\mathrm{Rx} 4)$ on $\mathrm{D} 9$ represented by stars. As shown in Fig. 1, D8 and D9 are connected by two stairways. "SW1" is located on the top right corner of the decks and contains Tx in its lower level (D8) and Rx1 at its higher level (D9). "SW2" is located in the middle. Each stairway has two metallic entrance doors at both D8 and D9. "Door 1" and "Door 2" are the two entrance doors of SW1 at D8 and D9 respectively, and "Door 3" is the entrance door of SW2 at D9. Firstly, for Rx1, the Tx and Rx are in the same vertical plan, but the Line-of-Sight ( $\mathrm{LoS}$ ) path is blocked by the metallic floor of D9. However, the wireless communication has a good quality and the received power is around $-48 \mathrm{dBm}$. Communication is possible thanks to the multipath propagation. Secondly, for Rx2 (located at $4.8 \mathrm{~m}$ from Door 2 and $8.8 \mathrm{~m}$ from Door 3), several cases have been studied with respect to the status of Door 1 and Door 2 (closed or open). When these two doors are open, the received power is around $-54 \mathrm{dBm}$. When closing only Door 2 (at D9), the received power decreases to $-74 \mathrm{dBm}$, which corresponds to a supplementary path loss of $20 \mathrm{~dB}$ with respect to the previous case. However, when closing both Door 1 and Door 2, the received power becomes $-68 \mathrm{dBm}$. Hence, the closure of Door 1 at D8 increases the received power at Rx2. This result proves that the main part of energy achieving Rx2 comes from SW1. Closing Door 1 reduced the radio leakage in D8 and kept the energy in SW1, in which it is then reflected to achieve Rx2. 
Thirdly, for Rx3 (located in front of Door 3 at $14 \mathrm{~m}$ from Door 2), when Door 1 is open and Door 2 is closed, the received power is $-77 \mathrm{dBm}$. It decreases to $-88 \mathrm{dBm}$ when closing Door 3 . This result shows that, in contrast with location $\mathrm{Rx} 2$, a part of energy achieving Rx3 propagates through SW2. Measurement results at Rx2 and Rx3 show that the received power increases when the $\mathrm{Rx}$ is located near stairways which may be sources of radio leakage between the two adjacent decks. This view explains the weakness of the received signal at $\mathrm{Rx} 4(-88 \mathrm{dBm})$ located far from stairways (at $32 \mathrm{~m}$ from Door 2 and $18 \mathrm{~m}$ from Door 3). Therefore, it is necessary to place nodes in stairways to maintain the connectivity of a shipboard WSN on different decks. These nodes may cover an area with a radius up to $15 \mathrm{~m}$ on the upper deck even when closing all stairways entrance doors. Opening the doors may increase the radius of radio coverage to $32 \mathrm{~m}$.

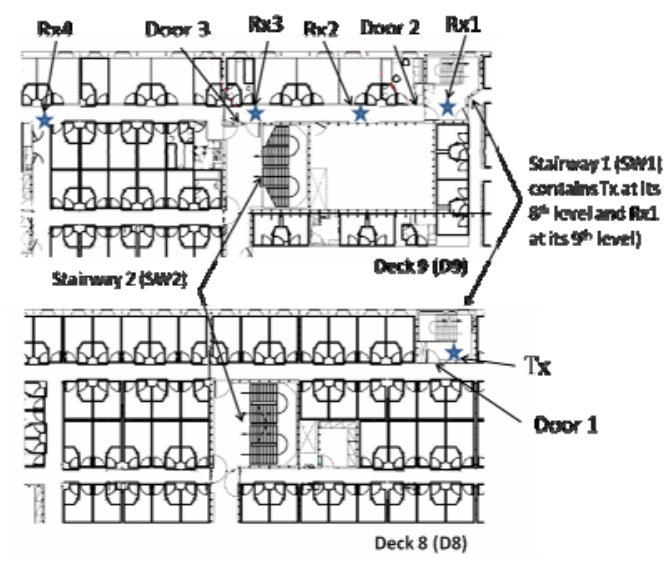

Fig. 1. Layout of Deck 8 and Deck 9.

\section{Double Directionnal Channel Measurements}

Results of CW measurements show that the received signal level increases when the Tx or Rx are close to stairways. It is worth mentioning that floors and ceilings are fully metallic on board "Armorique". EM waves propagation is very difficult through ceilings. The double directional channel sounding is a useful way to determine the sources of radio leakage between adjacent decks by studying the Directions of Departures (DoD) and the Directions of Arrivals (DoA) of EM waves. The used Multiple-Input Multiple-Output (MIMO) channel sounder is presented in [3]. A 4-elements Uniform Circular antenna Array (UCA) is used for the Tx and a 16-elements UCA for the Rx. With this measurement configuration we can characterize $360^{\circ}$ azimuthal double directional channel at both link sides. The Tx is located at the 7th deck (D7) which is an open hall containing restaurant and bars, with big glazed walls. This reduces the number of EM reflections and facilitates the separation of the main DoDs. The Rx is located on D8 within a stairway. The Tx is located at $25 \mathrm{~m}$ from the entrance door of the stairway that contains the Rx. D7 and D8 are connected by three stairways. The entrance doors of the first and third stairways were open during measurements, whereas the door of the second one was closed. We assume a quasi time-invariant channel during the measurements. Attention was paid that no people were moving in the surrounding area. Several measurements were taken and averaged to reduce the noise effect. The objective is to characterize the double directional channel impulse response, from which we gave a special attention to the DoDs and DoAs which are the most important parameters to determine EM leakage between adjacent decks. Collected data are analyzed using the high resolution algorithm SAGE [4]. Fig. 2 shows the power normalized (with respect to the strongest path) DoDs at the Tx side (represented by stars). Some principal propagation directions can be easily identified for the DoDs (at $0^{\circ}, 180^{\circ}$, $210^{\circ}$ and between $120^{\circ}$ and $150^{\circ}$ ). The most important paths are clearly directed to the two first stairways (at $180^{\circ}$ and between $120^{\circ}$ and $150^{\circ}$ ). This result shows that EM waves propagate mainly through "Stairway 1 " and "Stairway 2" that connect D7 and D8. A few number of paths pass through "Stairway 3". This measurement result confirms the conclusion drawn from the narrowband measurements, which considers that stairways are the main sources of radio leakage between adjacent decks.

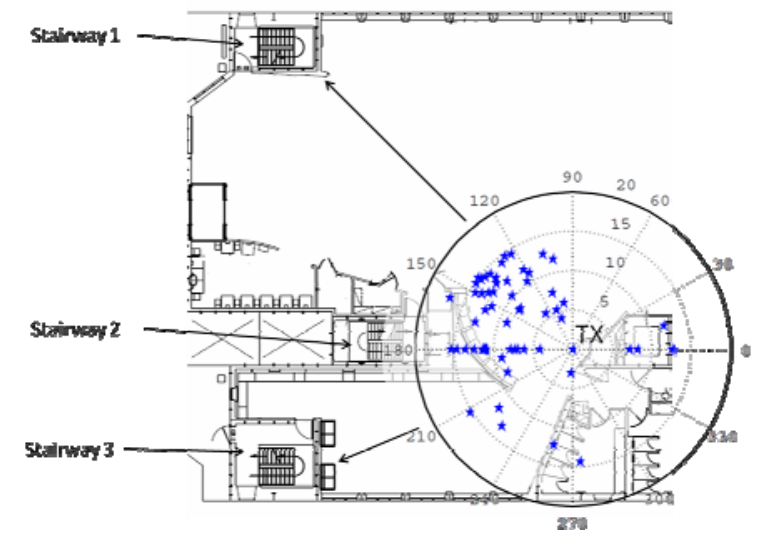

Fig. 2. SAGE estimated DODs.

\section{CONCLUSION}

This paper reports on narrowband and double directional channel measurements conducted on a modern ship to characterize the EM waves propagation between adjacent decks. In spite of the totally metallic structure of decks, the obtained results showed that inter-decks radio communication remains possible. EM waves propagate mainly through stairways. This observation brings interesting perspectives for wireless networks deployment in such a complex environment. It would be necessary to place nodes in the stairways to maintain the connectivity of a shipboard wireless network.

\section{REFERENCES}

[1] J. P. Lynch and K. Loh, "A summary review of wireless sensors and sensor networks for structural health monitoring," Shock. Vibr. Dig., pp. 91-128, 2006.

[2] M. Steinbauer, A. F. Molisch and E. Bonek, "The double-directional radio channel,” IEEE Ant. and Propag. Mag., August 2001, pp. 51-63.

[3] H. Farhat, R. Cosquer, G. Grunfelder, L. Le Coq and G. El Zein, “A dual band MIMO channel sounder at 2.2 and $3.5 \mathrm{GHz}$," Proc. of the IEEE I2MTC Conf., Victoria, Vancouver Island, May 2008, pp. 1980-1985.

[4] B. H. Fleury, M. Tschudin, R. Heddergott, D. Dahlhaus and K. I. Pedersen, "Channel parameter estimation in mobile radio environments using the SAGE algorithm,” IEEE J. S. A. C., 1999, 17, pp. 434-450. 